\title{
Whatsapp Addiction Affecting Students at Politeknik Sultan Mizan Zainal Abidin
}

\author{
Noor Rulhanim Binti Mohamad Ariffin ${ }^{1 *}$, Norhafiza Binti Idris ${ }^{2}$ \\ ${ }^{12}$ Politeknik Sultan Mizan Zainal Abidin \\ ఏ e-mail: noor.rulhanim@psmza.edu.my
}

\begin{abstract}
Nowadays, surfing the internet across virtual borders became a must to almost every layer of society. The existence of various social sites like Facebook, Twitter, Instagram and WhatsApp as medium to communicate became widely used because the internet is accessible to anyone regardless of place and time. Excessive use of WhatsApp is addictive and it gave different impact in terms of advantages and disadvantages to the users. Highlights from this, this paper work was done to assess the influence of the excessive use of WhatsApp on the attitude of students of PSMZA. A total of 250 students were randomly selected which consists of male and female students. The methodology used is descriptive method and quantitative approach that is using the questionnaire instrument consisting of three parts, namely part A respondent's demographic information, part $B$ of the information level of addiction to the use of WhatsApp and part $C$ information relating to the attitude of students either positive or negative towards their environment. The data collected is processed through the software IBM SPSS Statistics version 23. From the study it was found that the influence of the use of excessive WhatsApp still had positive impact on the attitudes of students of PSMZA. However, female students were more addicted to WhatsApp compared to male students.
\end{abstract}

Keywords:Addiction; WhatsApp; attitude; Internet

\section{Ketagihan Whatsapp Mempengaruhi Sikap Pelajar di Politeknik Sultan Mizan Zainal Abidin}

\begin{abstract}
Pada masa kini, melayari internet merentas sempadan maya menjadi suatu keharusan untuk hampir setiap lapisan masyarakat. Kewujudan pelbagai laman sosial seperti Facebook, Twitter, Instagram dan WhatsApp sebagai medium untuk berkomunikasi digunakan secara meluas kerana internet boleh diakses oleh sesiapa sahaja tanpa mengira tempat dan masa. Penggunaan berlebihan WhatsApp adalah ketagihan dan memberi kesan yang berbeza dari segi kelebihan dan kekurangan kepada pengguna. Sorotan dari ini, kerja kertas kerja ini telah dilakukan untuk menilai pengaruh penggunaan WhatsApp yang berlebihan terhadap sikap pelajar PSMZA. Seramai 250 pelajar dipilih secara rawak yang terdiri daripada pelajar lelaki dan perempuan. Metodologi yang digunakan adalah kaedah deskriptif dan pendekatan kuantitatif yang menggunakan instrumen soal selidik yang terdiri daripada tiga bahagian, iaitu bahagian A maklumat demografi responden, bahagian $B$ dari tahap ketagihan maklumat untuk penggunaan WhatsApp dan maklumat bahagian $C$ yang berkaitan dengan sikap pelajar sama ada positif atau negatif terhadap persekitaran mereka. Data yang dikumpulkan diproses melalui perisian Statistik SPSS IBM versi 23. Dari kajian itu didapati bahawa pengaruh penggunaan WhatsApp yang
\end{abstract}


berlebihan masih mempunyai kesan positif terhadap sikap pelajar PSMZA. Walau bagaimanapun, pelajar perempuan lebih ketagih kepada WhatsApp berbanding pelajar lelaki.

Keywords:Ketagihan; WhatsApp; sikap; Internet

\section{PENGENALAN}

Perkembangan pesat jaringan internet dan teknologi era kini tidak dinafikan memberi pelbagai manfaat kepada kita. Internet menjadi suatu keperluan asas kepada masyarakat kita dalam aspek kelajuan pencarian maklumat dan hiburan. Perkhidmatan internet yang disediakan oleh beberapa syarikat telco gergasi di Malaysia sememangnya amat mudah diakses di mana-mana tidak kira tempat dan masa dengan pakej harga internet yang berpatutan dan mampu milik. Tidak hairanlah apabila media sosial dilihat semakin menjadi pilihan utama sebagai platform untuk berkomunikasi dewasa ini. Perkembangan ini menjadi faktor utama penyumbang kepada kerancakan penggunaan aplikasi telefon pintar yang kelihatan semakin canggih dan sofistikated fungsinya. Telefon pintar menjadi kepemilikan tidak kira kepada golongan dewasa, tua, muda, remaja hatta kanak-kanak sekalipun. Rata-rata pengguna telefon pintar tidak ada yang tidak mempunyai aplikasi WhatsApp di telefon pintar mereka termasuklah pelajar-pelajar di Politeknik Sultan Mizan Zainal Abidin(PSMZA).

Aplikasi WhatsApp adalah aplikasi percuma yang boleh dimuat turun daripada Google Play untuk pengguna android dan App Store untuk pengguna ios. Pada aplikasiGoogle Play menunjukkan seramai satu billion pengguna telah memuat turun aplikasi WhatsApp di seluruh dunia. Turut dinyatakan juga bahawa WhatsApp menjadi pilihan nombor satu sebagai alat komunikasi yang percuma tanpa dikenakan bayaran tahunan. Boleh dikatakan kebanyakan rakyat Malaysia adalah pengguna WhatsApp.Majoriti pelajar PSMZA yang menjadi responden sememangnya memiliki aplikasi ini dan mereka merupakan pengguna WhatsApp yang aktif. WhatsApp mula diperkenalkansekitar tahun 2010, sekarang menjadi salah satu media saluran maklumat yang tidak dinafikan keberkesanannya tetapi penggunaanyang berlebihan akan mengundang keburukan jika tidak dapat mengawalnya. Menurut kajian yang dijalankan oleh Manap et al. (2016), remaja menggunakan WhatsApp selama 4.2 jam sehari iaitu suatu tempoh masa yang paling lama dan yang tertinggi berbanding penggunaan lain-lain media sosial diikuti oleh WeChat (2.6 jam), Facebook (1.8 jam) dan Instagram (1.8 jam). Dalam kajian Moro (2016), WhatsApp mampu mengubah sikap, gaya hidup, bahkan mengubah cara berperilaku, berkomunikasi, dan bersosialisasi dengan persekitaran sekeliling. Justeru itu, penulis telah melihat penggunaan WhatsApp ini sebagai trendi dan antara media sosial yang sangat popular digunakan sekarang.

Kajian Afgani. Y et all (2015) menyatakan bahawa penggunaan WhatsApp yang berlebihan akan menyebabkan ketagihan dimana akan memberikan impak negatif bagi kehidupan penggunanya secara sedar mahupun tidak sedar. Menyedari hakikat ini, kita perlu berusaha mendidik dan membantu meningkatkan kesedaran pengguna khususnya pelajar-pelajar PSMZA dalam menekankan kawalan kendiri terhadap penggunaanWhatsApp. Semoga selepas ini kita sama-sama dapat membantu membendung sikap pelajar daripada semakin hanyut dengan dunia komunikasi bisu.

\section{Pernyataan Masalah}

Penggunaan yang berlebihan bermaksud pengguna WhatsApp yang tidak dapat mengawal penggunaannya iaitu mereka tidak berjaya mengendalikan, mengurangkan atau menghentikan penggunaan WhatsApp. Contohnya, jika tidak menggunakan WhatsApp dalam sehari, pengguna tersebut akan berasa gelisah atau tidak sabar untuk melihat notifikasi WhatsApp hatta sedang memandu kereta, sedang menunggang motosikal dan walaupun sedang berjalan kaki mereka masih sempat membalas WhatsApp. Ini akan mengundang bahaya keselamatan diri. Berdasarkan hal ini, penulis melakukan kajian untuk mengenalpasti pengaruh ketagihan WhatsApp ke atas sikap pelajar pada masa kini. Justeru, penggunaan WhatsApp yang berlebihan akan memberi banyak kesan sampingan kepada pelajar. 
Antaranya pelajar kurang memberi tumpuan dalam pelajaran disebabkan pelajaran mereka terganggu dan tiada masa untuk mengulangkaji kerana terlampau asyik menggunakan WhatsApp.

\section{Objektif Kajian}

Objektif utama kajian ini adalah untuk:

1. Mengenalpasti sama ada terdapat perbezaan di antara jantina dengan sikap dalam kalangan pelajar Politeknik

1. Sultan Mizan Zainal Abidin

2. Mengenalpasti sama ada terdapat perbezaan di antara jantina dengan ketagihan WhatsApp dalam kalangan

3. pelajar Politeknik Sultan Mizan Zainal Abidin

4. Mengetahui sama ada terdapat perhubungan yang signifikan di antara sikap dengan ketagihan WhatsApp

5. dalam kalangan pelajar Politeknik Sultan Mizan Zainal Abidin.

\section{LITERATUR REVIEW}

\section{Sejarah WhatsApp, ketagihan dan kajian tentangnya.}

Aplikasi WhatsApp telah mula diperkenalkan secara rasmi oleh pengasasnya Jon Koum pada tahun 2010 dan ia semakin berkembang dan terus berkembang apabila berjaya menjadi popular dan menduduki carta top 20 di App Store pada tahun 2011. Melalui Play Store sahaja, lebih satu bilion pengguna dicatatkan telah memuat naik aplikasi ini di telefon pintar masing-masing. Menurut kajian yang dijalankan oleh Manap et al. (2016) WhatsApp adalah media sosial yang paling popular di kalangan remaja kerana ia mempunyai ciri - ciri yang lebih privasi berbanding media sosial yang lain. WhatsApp digunakan untuk berhubung secara kerap dengan rakan-rakan dan keluarga yang tinggal berjauhan untuk membina dan mengukuhkan jaringan persahabatan dengan kos yang menjimatkan. Hal ini memang tidak dinafikan kerana aplikasi WhatsApp adalah percuma sehingga tulisan kajian ini diterbitkan. Menurut Hj.Mumin (2017) semenjak internet semakin mudah diakses, penyebaran maklumat berlaku dengan cepat dan tepat. Transformasi telefon pintar menunjukkan peningkatan pengaruh kemajuan teknologi. Hal yang demikian menyebabkan penggunaan WhatsApp semakin mendapat tempat di hati pengguna.

Walaubagaimanapun, penggunaan WhatsApp yang berlebihan sehingga membawa kepada ketagihan akan memudaratkan dan meninggalkan kesan yang negatif. Ini disokong oleh kajian yang telah dijalankan oleh Afgani. Y et all (2015) mengenai penyalahgunaan aktiviti internet dan ketagihan WhatsApp menyatakan bahawa penggunaan internet dalam aktiviti aplikasi WhatsApp yang melebihi had untuk urusan peribadi dan hiburan pada masa yang tidak bersesuaian merupakan tanda-tanda bahawa penggunanya mengalami ketagihan WhatsApp. Menurut Young (1999), untuk mengenalpasti pengguna internet yang mengalami ketagihan atau tidak, beliau telah menguji pengguna dengan instrumen yang sama dengan kriteria untuk ketagihan perjudian. Begitu juga dengan penggunaan WhatsApp. Mereka yang menggunakan WhatsApp akan berasa gelisah jika tidak dapat menggunakan WhatsApp dalam sehari. Antara tanda-tanda pengguna WhatsApp yang ketagihan ialah mereka tidak berjaya mengendalikan, mengurangkan atau menghentikan penggunaan WhatsApp.

Dari segi impak positifnya, penggunaan WhatsApp sebenarnya dapat memberikan banyak kebaikan kerana menurut Ma'mun (2015), WhatsApp bukan sahaja digunakan sebagai medium untuk komunikasi tetapi juga sebagai platform untuk perniagaan selain diaplikasikan WhatsApp ke dalam sistem pengajaran dan pembelajaran. Menurut Tahir, \& Mohd.Yusof (2017) dalam kajiannya bertajuk Kepentingan Penggunaan Media Sosial Teknologi Maklumat Dalam Pendidikan IPTA berpendapat bahawa penggunaan media sosial dalam Pengajaran dan Pembelajaran (P\&P) adalah penting seiring dengan perkembangan dunia pendidikan moden pada masa kini. Ini akan mewujudkan suasana P\&P yang menyeronokkan dan lebih kondusif. Hal ini turut diakui dalam kajian Hussin, Norul 'Azmi \& Mat Daud (2017) mengenai penggunaan WhatsApp dalam meningkatkan motivasi pelajar dalam pembelajaran kolaboratif.Manakala menurut Musa, \& Tasir (2010) mendapati bahawa internet dan alatan rangkaian sosial mampu membina amalan pembelajaran terarah kendiri iaitu akan mewujudkan suasana 
pembelajaran aktif. Secara tidak langsung ia memberi peluang kepada pelajar untuk mencari maklumat, mengumpul bahan-bahan penting untuk rujukan mereka sendiri, berkomunikasi dan membuat penilaian. Selain daripada itu, WhatsApp banyak membantu pelajar-pelajar untuk berhubung dan bekerjasama dalam menyelesaikan tugasan dan melakukan perbincangan dalam kumpulan dengan lebih efektif. Di samping itu juga, mengikut Saari, \& Mahiyaddin (2017) menyatakan bahawa penggunaan aplikasi WhatsApp dapat membantu pelajar dalam penguasaan bahasa di kalangan mereka. Ini diperkukuhkan lagi dengan kajian Moro (2016) yang berpendapat bahawa Penggunaan WhatsApp memberikan pengaruh terhadap prestasi belajar mahasiswa, walaupun bukan sebagai faktor utama.

Sementara itu, kajian yang telah dijalankan dalam kalangan belia Malaysia oleh Lee et al. (2016) menyatakan bahawa golongan belia lebih suka berkongsi informasi yang menarik dengan rakan-rakan menerusi aplikasi seperti WhatsApp kerana WhatsApp berfungsi sebagai tempat pencarian dan perkongsian maklumat di samping pendekatan yang lebih mudah dan penggunaannya dalam penjimatan kos. Mereka juga sentiasa membawa telefon pintar mereka ke hulu ke hilir dan akan memeriksa sama ada terdapat mesej baharu dalam WhatsApp mereka. Pautan berita-berita hangat mahupun sensasi sering dihantar kepada mereka menerusi perkhidmatan WhatsApp oleh rakan-rakan. Hal ini menunjukkan bahawa kebergantungan remaja belia masa kini sangat mementingkan aktiviti-aktiviti di atas talian terutama WhatsApp dan media sosial yang lain amnya.

Selain daripada penggunaan WhatsApp dalam pembelajaran dan pencarian infomasi, kebaikan WhatsApp juga dapat dilihat dalam konsep berdakwah. Dalam kajian Rohimah(2017) menyatakan tentang keberkesanan pengurusan berdakwah melalui kumpulan WhatsApp dan kajian ini disokong oleh kajian Ismail \& Ashaari (2018) bahawa WhatsApp dapat membantu penyebaran dakwah dengan lebih fleksibel kerana pendakwah boleh berkongsi maklumat secara langsung dan berinteraksi dengan khalayak sasaran dengan lebih interaktif. Melalui WhatsApp aktiviti berdakwah dapat disampaikan secara teks, video dan juga audio. Tanpa diragui sudah semestinya ini membolehkan mesej dakwah dapat disampaikan dengan pantas, mudah dan fleksibel.

\section{WhatsApp Mempengaruhi Sikap Negatif Pengguna.}

Merujuk kepada Dewan Bahasa dan Pustaka, sikap bererti gaya iaitu lagak, tingkah laku, gerakgeri, rupa, perilaku, atau perangai. Penggunaan WhatsApp yang berlebihan boleh mempengaruhi sikap pengguna. Dalam kajian Putri, Nurwati \& Budiarti S (2016) mendapati bahawa remaja yang terpengaruh dengan media sosial melalui aplikasi WhatsApp menampilkan perangai yang berbeza ketika berada di alam maya dan dunia nyata. Mereka bebas berkomentar dan menyatakan pendapat tanpa rasa khuatir walaupun menyentuh sensitiviti seseorang. Menurut Manap et al. (2016) remaja yang aktif menggunakan media sosial akan mengalami masalah kemahiran komunikasi secara bersemuka dan banyak membazirkan masa sekaligus mengabaikan tanggungjawab. Kajian Mustafa (2011)(dalam Afgani. Y et all, 2015) menyatakan bahawa masalah psikologi seperti kemurungan, kesepian, kerap tertekan, dan kebimbangan akan berlaku kepada pengguna yang mengalami ketagihan internet melalui aplikasi WhatsApp. Kini, tidak hairanlah jika kita melihat seseorang remaja atau pengguna media sosial itu dilihat lebih mesra di atas talian berbanding di dunia nyata. Dalam erti kata lain, wujudnya ramai keyboard warriors yang tahu menulis di laman sosial tetapi mempunyai komunikasi yang kurang berkesan di dunia nyata.

Selain daripada itu, menurut Fauzi(2017) WhatsApp juga telah disalahgunakan oleh sesetengah pengguna sebagai alat untuk menyebarkan fitnah dan maklumat-maklumat yang salah dan tidak tepat. Salah satu cabaran yang dihadapi adalah berkenaan dengan ketulenan atau kesahihan sesuatu berita atau maklumat yang dibaca di media sosial. Dengan informasi di hujung jari masyarakat khususnya para belia terdedah dengan pelbagai bentuk berita atau maklumat yang palsu. Kebanyakan masyarakat Malaysia khususnya belia dan remaja amat mudah terpengaruh dengan fitnah atau tohmahan yang terdapat dalam media sosial.

Fenomena buli siber juga dipengaruhi oleh perkembangan media sosial. Menurut kajian Che Noh \& Ibrahim (2014) kejadian dan jenis tingkahlaku yang berkaitan dengan buli siber dalam kalangan pelajar institusi pengajian tinggi berlaku melalui jaringan sosial kerana masyarakat kini mempunyai akses yang 
mudah terhadap teknologi komunikasi. Pendapat ini menguatkan lagi kajian berkaitan buli siber apabila Wan Embong et.al (2015) dalam kajiannya menyatakan bahawa aplikasi WhatsApp merupakan medium kedua tertinggi yang digunakan oleh pelajar untuk membuli pelajar lain dalam kalangan mahasiswa selepas facebook. Hal ini sudah tentu memberikan kesan yang negatif terhadap WhatsApp. Penggunaan secara tidak terkawal atau tanpa etika boleh mengundang pelbagai implikasi, malah lebih buruk boleh memporak-perandakan masyarakat.

\section{METODOLOGI}

Responden yang dipilih dalam kajian ini adalah secara rawak bebas iaitu seramai 250 orang. Cara pemilihan jumlah sampel ini adalah berdasarkan jadual penentuan saiz sampel yang disediakan oleh Cohen (2011). Oleh itu, memandangkan jumlah pelajar PSMZA adalah seramai 3913 orang, maka saiz sampel yang diperlukan adalah 250 orang responden. Responden ini terdiri daripada pelajar-pelajar Teknologi Maklumat, Kejuruteraan Mekanikal, Kejuruteraan Awam dan Kejuruteraan Elektrikal di Politeknik Sultan Mizan Zainal Abidin. Usia responden adalah dalam lingkungan 18-26 tahun. Kajian ini dijalankan secara kuantitatif dengan menggunakan soal selidik yang terdiri daripada tiga bahagian iaitu (1) Bahagian A: Maklumat Demografi Pelajar, (2) Bahagian B: Maklumat Tahap Ketagihan Penggunaan WhatsApp dan (3) Bahagian C: Sikap Pelajar. Setiap bahagian soalan ini dibina bagi mencapai tiga objektif kajian iaitu mengenalpasti perbezaan di antara jantina dengan sikap, jantina dengan ketagihan WhatsApp dan adakah wujudnya hubungan yang signifikan antara sikap dengan ketagihan yang membawa kepada persoalan di mana penggunaan WhatsApp yang berlebihan mempengaruhi sikap pelajar di PSMZA.

Jadual 1. : Perincian Bahagian Borang Soal Selidik

\begin{tabular}{clcc}
\hline Bahagian & \multicolumn{1}{c}{ Penyataan } & $\begin{array}{c}\text { Bilangan } \\
\text { Item }\end{array}$ & Pembolehubah \\
\hline A & Maklumat Demografi Pelajar & 5 & Bebas \\
B & Tahap Ketagihan Penggunaan WhatsApp & 16 & Bersandar \\
C & Sikap Pelajar Terhadap Kebaikan dan Keburukan & 15 & Bersandar \\
& WhatsApp & Total Item & $\mathbf{3 6}$ \\
\end{tabular}

Setiap item soal selidik menggunakan skala likert seperti berikut :

Jadual 2. : Skala Likert Yang Digunakan

\begin{tabular}{ccc}
\hline Skor Skala Likert & Indikator \\
\hline 1 & Sangat Tidak Setuju \\
2 & Tidak Setuju \\
3 & Setuju \\
4 & Sangat Setuju \\
\hline
\end{tabular}

Skala Kurang Pasti atau Kurang Setuju digugurkan dalam item soal selidik supaya tidak mengelirukan responden untuk menjawab soal selidik ini Cohen(2011). Sebelum responden menjawab soal selidik, mereka diingatkan agar menjawab kesemua item yang telah diberikan dengan jujur. Setelah kesemua item soal selidik telah diisi dan dikumpulkan maka data dianalisis bagi menjawab objektif kajian.

\section{Kajian Rintis}

Kajian rintis telah dilaksanakan terhadap 30 responden. Nilai kebolehpercayaan diuji dengan menggunakan perisian Statistical Package for the Social Science (SPSS versi 23.0). Setelah dianalisis, indeks kebolehpercayaan soalan mempunyai nilai pekali Alpha Cronbach sebanyak 0.926 untuk kesemua 
soalan pada bahagian B dan C. Jika mengikut pecahan bahagian, bahagian B mempunyai nilai indeks kebolehpercayaan pekali Alpha Cronbach sebanyak 0.868 manakala bahagian C pekali Alpha Cronbach adalah 0.867. Menurut Mohamad Najib (1999), jika Pekali Alpha Cronbach di antara 0.8 hingga 1.0 bermakna item kajian boleh diterima dan tidak perlu ditukar dengan item lain. Maka soalan kaji selidik yang diedarkan oleh penulis adalah sesuai digunakan dalam kajian ini.

\section{DAPATAN KAJIAN DAN PERBINCANGAN}

Semua data diperoleh melalui edaran borang soal selidik. Jenis analisis data yang digunakan ialah Kolerasi Pearson dan Ujian-t bagi mengkaji hubungan di antara pembolehubah-pembolehubah yang melibatkan jantina, sikap, dan ketagihan WhatsApp

\section{Maklumat Demografi Responden}

Bahagian A dalam borang soal selidik ini merangkumi maklumat-maklumat peribadi responden yang berkaitan seperti jantina, bangsa, umur, jenis perkhidmatan internet ( sama ada prabayar atau pascabayar ) dan jumlah jam penggunaan WhatsApp dalam sehari. Rajah 1 menunjukkan taburan 250 responden yang terdiri daripada 141 pelajar lelaki $(56.4 \%)$ dan 109 pelajar perempuan (43.6\%).

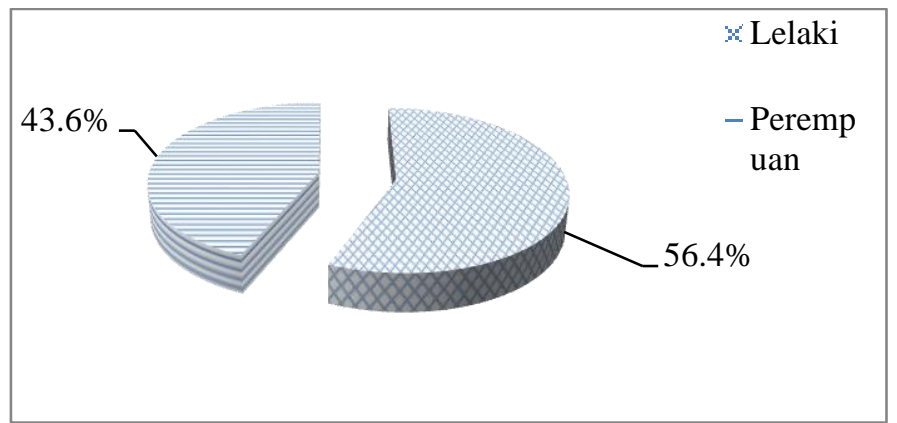

Rajah 1. : Taburan Responden Mengikut Jantina

Responden kajian ini terdiri daripada pelajar-pelajar PSMZA dalam lingkungan umur 18 hingga 26 tahun. Jadual 3 menunjukkan taburan umur responden yang menjawab soal selidik ini.

Jadual 3. : Taburan Responden Mengikut Umur

\begin{tabular}{ccc}
\hline Umur(tahun) & $\begin{array}{c}\text { Bilangan } \\
\text { Responden } \\
\text { (orang) }\end{array}$ & Peratus (\%) \\
\hline 18 hingga 20 & 199 & 79.6 \\
21 hingga 23 & 46 & 18.4 \\
24 hingga 26 & 5 & 2.0 \\
Total & 250 & \\
\hline
\end{tabular}

Rajah 2 pula menunjukkan etnik responden yang menjawab item soal selidik. Majoriti responden adalah berbangsa melayu iaitu seramai 237 orang Melayu (94.8\%), diikuti oleh 2 orang berbangsa Cina $(0.8 \%), 7$ orang India $(2.8 \%)$ dan 4 orang lain-lain etnik $(1.6 \%)$ 


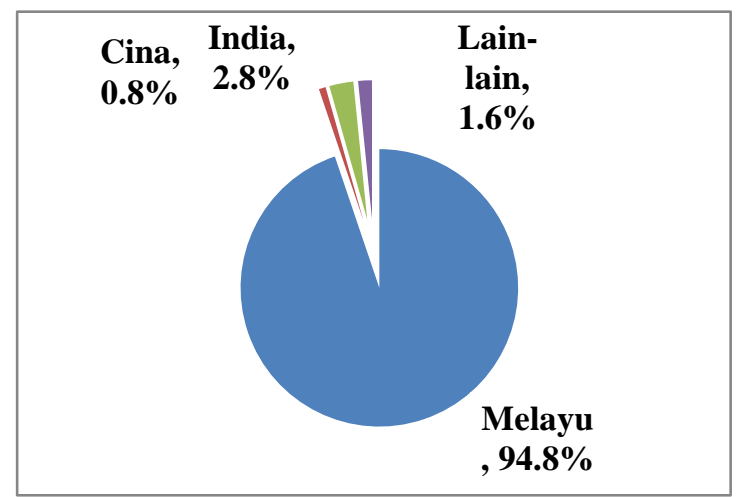

Rajah 2 : Taburan Responden Mengikut Bangsa

Rajah 3 menunjukkan jenis perkhidmatan internet yang dipilih oleh responden sama ada prabayar atau pascabayar. Seramai 206 orang $(82.4 \%)$ responden memilih untuk menggunakan perkhidmatan prabayar berbanding perkhidmatan pascabayar iaitu seramai 44 orang (17.6\%) sahaja. Pemilihan jenis perkhidmatan ini bergantung kepada latar belakang ekonomi responden masing-masing.

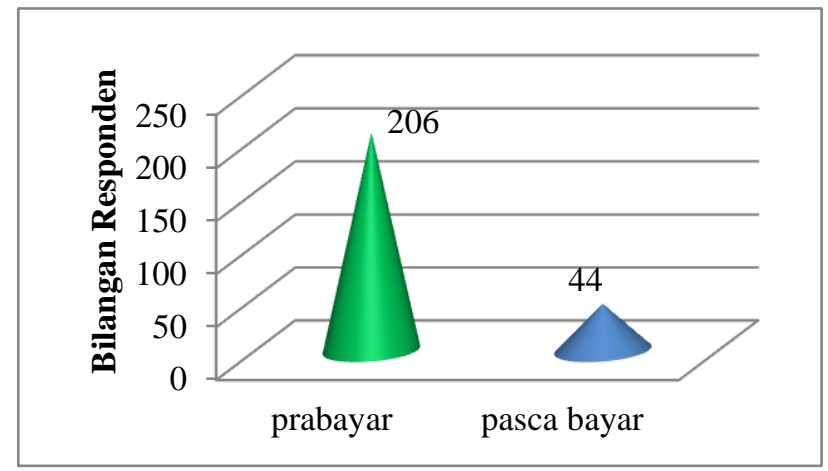

Rajah 3 : Jenis Perkhidmatan Internet Yang Dilanggani Prabayar Atau Pascabayar

Jadual 4. : Penggunaan WhatsApp Dalam Sehari (Dalam Jam)

\begin{tabular}{ccc}
\hline Jumlah Jam Sehari & Bilangan Responden & Peratus Penggunaan \\
\hline 0 hingga 2 & 49 & 19.6 \\
2 hingga 3 & 86 & 34.4 \\
4 jam ke atas & 115 & 46.0 \\
Total & 250 & \\
\hline
\end{tabular}

Manakala Jadual 4 di atas menunjukkan bilangan responden bagi penggunaan WhatsApp dalam sehari mengikut jam. Seramai 115 orang responden telah menggunakan WhatsApp melebihi 4 jam dan ke atas, diikuti 86 orang yang menggunakan WhatsApp antara 2 hingga 3 jam sehari dan hanya 49 orang responden yang menggunakan WhatsApp dalam tempoh 2 jam ke bawah dalam sehari. Ini menunjukkan tahap penggunaan WhatsApp yang aktif dalam kalangan responden.

\section{Maklumat Tahap Ketagihan Penggunaan WhatsApp}

Item soal selidik bahagian B adalah berkaitan dengan tahap ketagihan WhatsApp dalam kalangan responden. Terdapat 16 item soalan yang dibina oleh penulis berpandukan Ujian Ketagihan InternetInternet Addiction Test (IAT) yang dibangunkan oleh Dr. Kimberly Young, iaitu seorang psikologi klinikal di USA. Penulis telah merujuk skor markah Ujian IAT Young sebagai indikator bagi menilai tahap ketagihan WhatsApp dalam kalangan responden. Cara interpretasi skor mengikut Young (1999) melalui Hassan, \& Raja Abdul Rashid (2012) adalah seperti yang ditunjukkan seperti jadual 5 berikut: 
Jadual 5 : Interpretasi Skor Mengikut Young

\begin{tabular}{|c|c|c|}
\hline Jumlah Skor & Interpretasi Skor & $\begin{array}{l}\text { Keterangan Skor } \\
\text { Mengikut Young } \\
\end{array}$ \\
\hline 0 hingga 19 & Pengguna tidak ketagih & - \\
\hline 20 hingga 49 & Rendah & $\begin{array}{l}\text { Pengguna yang sedikit } \\
\text { ketagih. Pengguna } \\
\text { mungkin banyak } \\
\text { menghabiskan masa di } \\
\text { internet tetapi masih } \\
\text { dapat mengawalnya }\end{array}$ \\
\hline 50 hingga 79 & Sederhana & $\begin{array}{l}\text { Pengguna mengalami } \\
\text { masalah biasa kerana } \\
\text { internet.Pengguna perlu } \\
\text { memastikan kesan } \\
\text { menyeluruhnya dalam } \\
\text { kehidupan. }\end{array}$ \\
\hline 80 hingga 100 & Tinggi & $\begin{array}{l}\text { Penggunaan internet } \\
\text { membawa kesan yang } \\
\text { mendalam dalam hidup } \\
\text { pengguna. Pengguna } \\
\text { patut memikirkan } \\
\text { keburukannya kepada } \\
\text { diri sendiri dan } \\
\text { mengaku bahawa ini } \\
\text { semua disebabkan } \\
\text { kelalaian menggunakan } \\
\text { internet }\end{array}$ \\
\hline
\end{tabular}

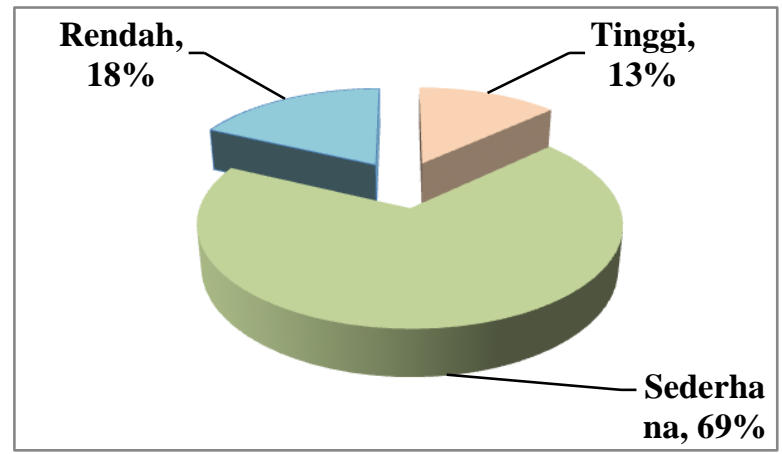

Rajah 4 : Tahap Ketagihan WhatsApp Dalam Kalangan Pelajar PSMZA

Berdasarkan rajah 4 di atas, hasil dapatan kajian mendapati bahawa bilangan responden yang mempunyai tahap ketagihan WhatsApp yang tinggi adalah seramai 33 orang (13\%) sahaja iaitu terdiri daripada 17 lelaki dan 16 perempuan. Majoriti bilangan responden adalah berada pada tahap ketagihan yang sederhana iaitu seramai 172 orang (69\%) terdiri daripada 92 lelaki dan 80 perempuan. Manakala seramai 45 orang (18\%) iaitu 32 lelaki dan 13 perempuan berada pada tahap ketagihan WhatsApp yang 
rendah. Walau bagaimanapun, tidak ada responden yang mendapat skor 0 hingga 19 markah yang memberi maksud ciri-ciri pengguna tidak ketagih.

Jadual 6.: Taburan Min Bagi Ketagihan WhatsApp Mengikut Faktor Jantina

\begin{tabular}{cccc}
\hline Jantina & $\mathbf{N}$ & Min & Sp \\
\hline Lelaki & 141 & 2.4109 & 0.62102 \\
Perempuan & 109 & 2.5614 & 0.56276 \\
\hline
\end{tabular}

Melalui hasil dapatan min seperti Jadual 6, min bagi ketagihan WhatsApp dalam kalangan pelajar perempuan adalah lebih tinggi berbanding min pelajar lelaki. Ini bermaksud responden dalam kalangan pelajar perempuan lebih ketagih atau lebih banyak menggunakan WhatsApp secara berlebihan berbanding pelajar lelaki. Namun, ketagihan ini masih di tahap sederhana berpandukan jadual pengkelasan tahap nilai skor min bagi empat skala yang digunapakai oleh (Ghani Hj. Taib,1996)

Jadual 7.: Jadual Interpretasi Tahap Min Empat Skala

\begin{tabular}{cc}
\hline Selang Skala Min & Interpretasi Tahap Min \\
\hline 1.00 hingga 2.00 & Rendah \\
2.01 hingga 3.00 & Sederhana \\
3.01 hingga 4.00 & Tinggi \\
\hline
\end{tabular}

Sumber: Ghani Hj.Taib (1996)

\section{Sikap Pelajar}

Bahagian $\mathrm{C}$ mengandungi 15 soalan merangkumi sikap pelajar terhadap kebaikan dan keburukan WhatsApp. Item yang berunsur pengaruh positif terdiri daripada 6 soalan dan 9 item berunsur pengaruh negatif. Min keseluruhan yang diperoleh untuk sikap yang positif ialah 3.32 iaitu lebih tinggi daripada min untuk sikap negatif, 2.25 .

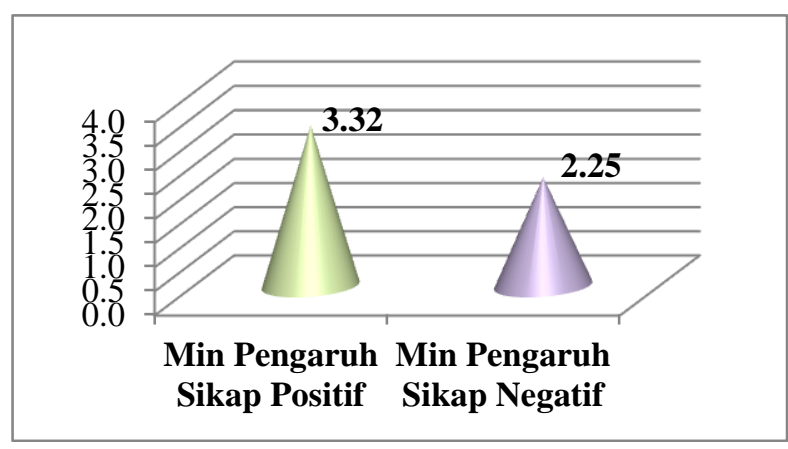

Rajah 5: Menunjukkan Nilai Min Pengaruh Sikap Positif dan Negatif Dalam Kalangan Responden

Jadual 8 di bawah menunjukkan analisis dapatan mengikut perincian soalan untuk min dan sisihan piawai berhubung dengan kesan WhatsApp ke atas pengaruh sikap positif dan sikap negatif.

Jadual 8:Analisis Min dan Sisihan Piawai (SP) Bagi Ketagihan WhatsApp Ke Atas Pengaruh Sikap Positif

\begin{tabular}{|c|c|c|c|}
\hline $\begin{array}{l}\text { Item Soalan } \\
\text { (Soalan } 1 \text { hingga 6) }\end{array}$ & Min & SP & $\begin{array}{l}\text { Interpretasi } \\
\text { Tahap Min }\end{array}$ \\
\hline 1. Saya menggunakan WhatsApp untuk mengetahui isu semasa. & 3.32 & .797 & Tinggi \\
\hline $\begin{array}{l}\text { 2. WhatsApp dapat memberikan informasi dan hiburan kepada } \\
\text { saya. }\end{array}$ & 3.20 & .807 & Tinggi \\
\hline
\end{tabular}


3. Penggunaan WhatsApp mampu menjimatkan kos untuk $3.61 \quad .638 \quad$ Tinggi berhubung dengan ibu bapa dan rakan-rakan

4. Saya selalu menggunakan WhatsApp untuk membuat
perbincangan tugasan (assignment) bersama rakan-rakan $3.56-675$ Tinggi sekumpulan

5. WhatsApp membantu saya dalam penguasaan bahasa Inggeris

$\begin{array}{lll}2.98 & .887 & \text { Sederhana } \\ 3.25 & .941 & \text { Tinggi }\end{array}$

6. Saya pernah terlibat dalam urusan jual beli dengan $3.25 \quad .941$ Tinggi menggunakan WhatsApp sebagai medium perantara

Daripada jadual 8 di atas, didapati bahawa skor min yang paling tinggi adalah untuk item no.3 diikuti oleh item no.4. Hal ini menunjukkan responden memilih WhatsApp pada tahap yang tinggi sebagai alat perhubungan untuk berhubung dengan ibu bapa dan rakan-rakan kerana ia menjimatkan kos disamping WhatsApp membantu mereka membuat perbincangan dalam kumpulan bagi menyelesaikan tugasan kuliah. Skor yang paling rendah adalah item no.5 iaitu responden bersetuju pada tahap yang sederhana bahawa WhatsApp membantu mereka meningkatkan penguasaan bahasa Inggeris.

Jadual 9: Analisis Min Dan Sisihan Piawai (SP) Bagi Ketagihan WhatsApp Ke Atas Pengaruh Sikap Negatif

\begin{tabular}{|c|c|c|c|}
\hline $\begin{array}{c}\text { Item Soalan } \\
(\text { Soalan 7 hingga 15) } \\
\end{array}$ & Min & SP & $\begin{array}{l}\text { Interpretasi } \\
\text { Tahap Min }\end{array}$ \\
\hline $\begin{array}{l}\text { 7. Semasa kuliah sedang berlangsung, saya kerap melihat } \\
\text { WhatsApp secara sembunyi-sembunyi }\end{array}$ & 2.30 & .912 & Sederhana \\
\hline $\begin{array}{l}\text { 8. Saya lebih mudah bertanya soalan kepada pensyarah } \\
\text { menggunakan WhatsApp berbanding face to face }\end{array}$ & 2.74 & 1.005 & Sederhana \\
\hline 9. Saya pernah meniru kuiz/assignment menggunakan WhatsApp & 2.19 & 1.065 & Sederhana \\
\hline $\begin{array}{l}\text { 10. Saya pernah bergaduh/berperang dalam WhatsApp bersama } \\
\text { rakan dalam kumpulan WhatsApp kerana tidak puas hati akan } \\
\text { sesuatu }\end{array}$ & 2.44 & 1.063 & Sederhana \\
\hline $\begin{array}{l}\text { 11. Saya pernah menyebarkan gossip, lawak jenaka atau fitnah } \\
\text { melalui WhatsApp }\end{array}$ & 2.19 & 1.030 & Sederhana \\
\hline $\begin{array}{l}\text { 12. Kadang-kadang saya lebih suka berWhatsApp daripada berbual } \\
\text { dengan orang lain. }\end{array}$ & 2.15 & 1.021 & Sederhana \\
\hline $\begin{array}{l}\text { 13. Saya pernah membaca dan membalas WhatsApp ketika sedang } \\
\text { berjalan kaki atau sedang memandu kereta atau sedang } \\
\text { menunggang motosikal ke kuliah/balik dari kuliah }\end{array}$ & 2.59 & 1.038 & Sederhana \\
\hline 14. Saya banyak menghabiskan masa menggunakan WhatsApp & 2.18 & .964 & Sederhana \\
\hline $\begin{array}{l}\text { 15. Saya pernah menggunakan WhatsApp sebagai medium untuk } \\
\text { menyebarkan gambar lucah kepada rakan-rakan dalam } \\
\text { kumpulan WhatsApp (GroupWhatsapp) }\end{array}$ & 1.47 & .879 & Rendah \\
\hline
\end{tabular}

Daripada jadual 9 di atas, didapati skor min untuk keseluruhan item adalah berada di tahap sederhana. Item no.8 adalah yang tertinggi diikuti oleh item no.13. Responden menggunakan WhatsApp untuk bertanyakan soalan kepada pensyarah bagi mendapatkan jawapan dan informasi dengan lebih pantas berbanding pergi bersemuka dengan pensyarah untuk bertanyakan soalan. Keadaan ini menunjukkan responden lebih suka berkomunikasi di alam maya berbanding di dunia nyata. Realitinya, walaupun kelihatan remeh tetapi memberikan impak yang besar dalam gaya komunikasi responden. Bagi 
item no.13, responden menggunakan WhatsApp ketika sedang memandu kenderaan dan berjalan kaki sebenarnya boleh mengundang bahaya dan mengancam keselamatan diri. Sikap ini perlu dielakkan kerana mereka perlu bijak mengendalikan penggunaan WhatsApp ketika sedang berjalan kaki atau sedang memandu kenderaan. Cara untuk mengawal penggunaan WhatsApp sangat penting kerana ia boleh mendatangkan kemudaratan kepada pengguna jika tidak mampu mengawal dengan baik. Secara keseluruhannya penggunaan WhatsApp dalam kalangan responden masih di bawah pengaruh sikap yang positif berdasarkan tahap penilaian skor min tersebut.

\section{Analisis Data Bahagian Objektif Kajian}

\section{Objektif 1: Mengenalpasti Sama Ada Terdapat Perbezaan Di Antara Jantina Dengan Sikap} Dalam Kalangan Pelajar Politeknik Sultan Mizan Zainal Abidin

Bagi mengenalpasti sama ada terdapat perbezaan di antara jantina dengan sikap dalam kalangan responden, penulis telah menggunakan ujian-t sampel bebas (independent t-test) untuk mengetahui jika terdapat hubungkait di antara kedua-dua pembolehubah tersebut.

Jadual 10: Perbezaan Sikap Mengikut Faktor Jantina

\begin{tabular}{cccccccc}
\hline Demografi & Faktor & $\mathbf{N}$ & Min & sp & dk & t & Sig(2-tailed) \\
\hline Jantina & Lelaki & 141 & 2.6960 & 0.5643 & 248 & 0.594 & 0.553 \\
& Perempuan & 109 & 2.6550 & 0.5086 & 242.2 & & \\
\hline
\end{tabular}

Hasil kajian menunjukkan bahawa nilai sig(2-tailed) berada di atas paras 0.05 maka dapat dirumuskan bahawa tidak terdapat perbezaan signifikan terhadap sikap dan faktor jantina bagi responden lelaki dan perempuan. Ini bermaksud sikap pelajar tidak dipengaruhi oleh jantina lelaki atau pun perempuan.

\section{Objektif 2 : Mengenalpasti Sama Ada Terdapat Perbezaan Di Antara Jantina Dengan Ketagihan WhatsApp Dalam Kalangan Pelajar Politeknik Sultan Mizan Zainal Abidin}

Penulis telah menggunakan ujian-t sampel bebas untuk mengetahui jika terdapat hubungkait di antara kedua-dua pembolehubah iaitu faktor jantina dan ketagihan WhatsApp.

Jadual 11: Perbezaan Ketagihan WhatsApp Mengikut Faktor Jantina

\begin{tabular}{cccccccc}
\hline Demografi & Faktor & $\mathbf{N}$ & Min & sp & dk & t & Sig(2-tailed) \\
\hline Jantina & Lelaki & 141 & 2.4109 & 0.621 & 248 & -1.978 & 0.049 \\
& Perempuan & 109 & 2.5614 & 0.563 & 241.8 & & \\
\hline
\end{tabular}

Hasil kajian mendapati nilai sig(2-tailed) berada di bawah paras 0.05 maka dapat dirumuskan bahawa terdapat perbezaan signifikan untuk ketagihan WhatsApp terhadap responden lelaki dan perempuan. Ini bermaksud ketagihan WhatsApp dipengaruhi oleh faktor lelaki dan perempuan.

\section{Objektif 3 :Mengetahui Sama Ada Terdapat Hubungan Yang Signifikan Di Antara Sikap Dengan Ketagihan WhatsApp Dalam Kalangan Pelajar Politeknik Sultan Mizan Zainal Abidin.}

Bagi mengenalpasti sama ada terdapat hubungan di antara sikap dan ketagihan WhatsApp dalam kalangan responden, penulis telah menggunakan ujian korelasi untuk mengetahui perhubungan di antara kedua-dua pembolehubah tersebut. 
Jadual 12: Hubungan Antara Ketagihan WhatsApp Dengan Sikap Responden

\begin{tabular}{ccc}
\hline Pembolehubah & Korelasi Pearson $(\mathbf{r})$ & Sig. (2-tailed) \\
\hline ketagihan & $.706^{* * *}$ & .000 \\
\hline & & $* *$ Correlation is significant at the 0.01 level (2-tailed).
\end{tabular}

Daripada hasil kajian di atas, nilai sig.(2-tailed) bagi sikap dan ketagihan WhatsApp ialah di bawah paras 0.05 . Ini bererti terdapat perkaitan yang signifikan antara sikap dan ketagihan WhatsApp. Manakala pekali Pearson bernilai 0.706 menunjukkan terdapat hubungan di antara ketagihan WhatsApp dan sikap responden. Dari segi kekuatan perkaitan, dapat dirumuskan bahawa mengikut Piaw (2012) tafsiran kekuatan perkaitan hubungan pekali, nilai 0.706 bermaksud terdapat perkaitan yang kuat antara kedua-dua pembolehubah tersebut. Hal ini dapat disimpulkan bahawa semakin tinggi ketagihan WhatsApp, maka semakin tinggi ia mempengaruhi sikap seseorang.

\section{Perbincangan}

Daripada kajian ini, dapat diketahui bahawa penggunaan WhatsApp memang popular kerana tidak dinafikan ia merupakan aplikasi yang paling berkesan untuk menyampaikan maklumat dan memburu informasi dengan cepat dan pantas. Ini mengukuhkan lagi kajian yang telah dijalankan oleh Abd Ghoni, Othman \& Abas (2017) di mana hasil kajiannya mendapati medium penyampaian maklumat yang paling baik dan berkesan adalah secara WhatsApp, kerana kaedah ini adalah kaedah yang paling pantas maklumat dapat disampaikan kepada pengguna-penggunanya. Dengan ini terbukti bahawa WhatsApp menjadi pilihan utama sebagai media perkongsian maklumat dengan memiliki ramai pengguna yang aktif sehingga mencecah satu billion pengguna.

Selain daripada itu, dapatan kajian ini menunjukkan bahawa responden perempuan lebih suka menggunakan WhatsApp secara berlebihan dalam erti kata lain responden wanita lebih ketagih WhatsApp berbanding responden lelaki. Walaubagaimana pun, sikap tidak dipengaruhi oleh faktor jantina atau ini bermaksud sikap tidak menunjukkan perkaitan dengan jantina seseorang tetapi ketagihan dan sikap saling terdapat perkaitan hubungan yang kuat. Dari segi pengaruh positif, di samping penggunaan WhatsApp sebagai saluran untuk mengetahui perkembangan isu semasa, mendapatkan maklumat dan berhubung dengan rakan-rakan dan ahli keluarga, WhatsApp juga dijadikan sebagai alat untuk berbincang perihal tugasan kuliah, meningkatkan penguasaan bahasa Inggeris selain daripada aktiviti berjual beli online. Dalam kajian Hassan, \& Raja Abdul Rashid (2012) ada dinyatakan bahawa penggunaan internet membantu pelajar dalam penguasaan bahasa. Ini terbukti bahawa, responden bersetuju dengan penggunaan WhatsApp dapat membantu mereka meningkatkan penguasaan bahasa Inggeris.

Dari segi pengaruh negatif, hasil dapatan kajian mendapati ada juga segelintir responden menyebarkan gambar lucah kepada rakan-rakan dalam kumpulan WhatsApp. Walaupun jumlahnya tidak ramai yang berkelakuan demikian tetapi perbuatan itu wujud. Manakala penyebaran gossip, lawak jenaka dan fitnah juga berlaku tetapi tidak ramai responden yang bersikap demikian. Mengikut kajian Ramli et al. (2015) WhatsApp bertindak sebagai platform penyebaran berita palsu atau khabar angin. Hal ini wujud kerana ruang komunikasi menjadi bertambah mudah dan penyebaran maklumat berlaku dengan pantas. Sebagai sebuah sistem komunikasi yang terbuka, maklumat dapat dipindahkan kepada pihakpihak lain secara lebih meluas dan murah sehingga memberi pelbagai impak kepada kehidupan manusia. Selain daripada itu, WhatsApp juga digunakan oleh segelintir responden sebagai saluran untuk meniru tugasan dan kuiz yang diberikan oleh pensyarah. Sikap ini perlu dikikis supaya jati diri responden dapat dipelihara dan mereka perlu menambah nilai-nilai positif dalam diri masing-masing. Menurut Syed Chear (2017) dalam kajiannya berkaitan dengan kesediaan dan keupayaan pelajar mengikuti pembelajaran melalui platform WhatsApp ia dapat membantu pelajar menguasai hasil pembelajaran. Dalam hemat penulis, jika sikap meniru ada dalam diri responden, ia tidak akan membantu dalam penguasaan hasil pembelajaran. Jika berlaku aktiviti tiru-meniru, ini bermakna pelajar tersebut masih belum bersedia untuk terdedah kepada m-pembelajaran. 


\section{KESIMPULAN}

Secara keseluruhan, data kajian ini menunjukkan bahawa pelajar perempuan di PSMZA lebih ketagih menggunakan WhatsApp berbanding dengan pelajar lelaki walaupun bilangan pelajar lelaki lebih ramai menjawab soalan kaji selidik ini. Tetapi ketagihan pelajar perempuan ini masih lagi di bawah pengaruh sikap yang positif. Tempoh penggunaan WhatsApp melebihi 4 jam ke atas tidak memberikan petunjuk bahawa seseorang itu mengalami ketagihan WhatsApp tetapi aktiviti di dalam WhatsApp yang menyebabkan tempoh penggunaan WhatsApp yang lama.

Dapatan kajian ini mengukuhkan lagi kajian Musafa et al. (2013) yang menunjukkan bahawa kebergantungan remaja terhadap internet melalui WhatsApp adalah untuk aktiviti bersembang. Mereka bersembang bagi mendapatkan maklumat untuk melakukan sesuatu tugasan, untuk berhibur, berkongsi minat dan meluahkan perasaan. Hasil kajian ini juga turut menjelaskan bahawa jantina tidak mempengaruhi sikap tetapi ketagihan WhatsApp mempengaruhi sikap sama ada sikap positif mahupun sikap negatif. Untuk mengawal pengaruh sikap supaya tidak memudaratkan, hanya pengguna yang mampu mengawal sikap itu sendiri. Kawalan kendiri dan disiplin amat penting dalam membendung pengaruh sikap yang tidak diingini. Pengguna-pengguna WhatsApp perlu bersosialisasi dengan baik di media sosial. Mereka perlu menyeimbangkan penggunaan teknologi dan bahan media yang boleh merosakkan mereka supaya tidak menjurus ke arah keburukan yang boleh menjejaskan identiti dan jati diri mereka sebagai pelajar yang bakal menerajui negara pada masa akan datang. Tanggungjawab keibubapaan amat penting dalam memantau aktiviti pelajar-pelajar di rumah. Komunikasi lisan yang berkesan antara setiap pelajar dan ibu bapa di rumah berupaya mendidik mereka cara berkomunikasi dengan betul. Penggunaan media sosial menerusi WhatsApp mampu memberikan kesan yang baik jika digunakan dengan cara yang betul.

Sebagai cadangan pada masa akan datang, kajian ini perlu diteruskan untuk mengkaji faktor-faktor mengapa golongan wanita lebih ketagihan WhatsApp berbanding golongan lelaki. Sikap dan tingkahlaku pengguna wanita dan lelaki memberikan pelbagai persepsi kepada kita bagaimana golongan-golongan ini berfikir dan bertindak. Kajian yang lebih mendalam akan memberikan hasil yang lebih terperinci terhadap kelakuan antara golongan wanita dan lelaki.

\section{DAFTAR PUSTAKA}

Abd Ghoni, S., Othman, A. \& Abas, N. (2017). Kajian Keberkesanan Penyampaian Maklumat Di Jabatan Kejuruteraan Elektrik, Polimas. e- Proceeding National Innovation and Invention Competition Through Exhibition (iCompEx17),

Afgani. Y et all (2015).Penyalahgunaan Aktiviti Internet dan Ketagihan WhatsAppp: Suatu Analisa Konseptual. Proceeding of International conference on Addiction Science : Holistic approach on the misuse and addiction management. Retrieved from https://www.academia.edu

Ahmad Taufiq Ma'mun. (2015). Efektivitas Pembelajaran Bahasa Arab Melaui Media Social whatsAppdi Program BISA (Belajar Islam \& Bahasa Arab). Tesis Sarjana , Jurusan Pendidikan BahasaArab, Fakultas Ilmu Tarbiyah \& Keguruan Universiti Islam Negeri Sunan Kalijaga

Che Noh, C. H. \& Ibrahim, M. Y. (2014). Kajian Penerokaan Buli Siber Dalam Kalangan Pelajar UMT. Procedia - Social and Behavioral Sciences, 134, 323-329. doi:10.1016/j.sbspro.2014.04.255

Cohen, L., Manion, L., \& Morisson, K (2011). Research Methods in Education (7th ed., Vol. 55). New York : Routledge. http://doi.org/10.1111/j.1467-8527.2007.00388_4.x

Fauzi, N. (2017). Penggunaan Media Sosial Dalam Dunia Tanpa Sempadan: Suatu Kebaikan Atau Keburukan? Institut Latihan Kehakiman dan Perundangan,.

Ghani Hj Talib, (1996). Pembinaan Instrumen: Ceramah Kursus Penyelidikan Pendidikan, Anjuran Bahagian Pendidikan Guru, Kementerian Pendidikan Malaysia, 12-13 Ogos 1996.

Hassan, J. \& Raja Abdul Rashid, R. S. (2012). Ketagihan penggunaan internet di kalangan remaja sekolah tingkatan 4 di bandaraya Johor Bahru. Journal of Technical, Vocational \& Engineering Education, 6(June), 23-43.

Hj.Mumin, N. H. (2017). Globalisasi dalam teknologi maklumat: tumpuan terhadap dakwah melalui biografi wanita. Journal Article, 
Hussin, N., Norul 'Azmi, N. A. \& Mat Daud, M. (2017). PEMBELAJARAN KOLABORATIF MELALUI APLIKASI TELEFON PINTAR DALAM PEMBELAJARAN NAHU. e-Jurnal Penyelidikan Dan Inovasi, 4(1), 43-63.

Ismail,NF. \& Ashaari,MF. (2018. Komunikasi Dakwah Dalam Interaksi Melalui WhatsApp.Fikiran Masyarakat, (Januari) , 6(1), 33 - 39

Lee Kuok Tiung, Meri, A., Mat Nayan, L. \& Othman, S. S. (2016). Kegunaan Dan Kepuasan Portal Berita Dalamkalangan Beliamalaysia. Kegunaan Dan Kepuasan Portal Berita Dalamkalangan Beliamalaysia, 32(2), 790-816.

Manap, J., Hamzah, M. R., Amin, A. S., Mohd Izani, N. N., Idris, F., Hamjah, S. H., Tambi, N. et al. (2016). Penggunaan dan Implikasi Media Sosial Terhadap Remaja Generasi Z. International Conference on Social and Economic Development, (November), 1-12. Retrieved from https://www.researchgate.net/publication/309668766

Mohamad Najib Abdul Ghafar, (1999). Penyelidikan Pendidikan. Skudai: Penerbit UTM.

Moro, H. K. E. P. (2016). Pengaruh Penggunaan Whats Apps Messenger terhadap prestasi belajar Mahasiswa kelas KKH di PBIO FKIP UAD (August), 1-9. Retrieved from https://www.researchgate.net/publication/309668766

Musa, A. \& Tasir, Z. (2010). Implikasi alatan rangkaian sosial terhadap proses pengajaran dan pembelajaran. Edupress 2010, 1-14. Retrieved from http://eprints.utm.my/14936/

Musafa, N., Wan Mahmud, W. A., Ahmad, F., Mahbob, M. H. \& Abd.Rahim, M. H. (2013). Kebergantungan Internet Dan Aktiviti. Kebergantungan Internet Dan Aktiviti Online Remaja, 29(1), 199-212.

Mustafa, KOÇ. (2011). Internet Addiction And Psychopatology. The Turkish Online Journal of Educational Technology, 10(1) 143-148

Piaw, C. Y.(2012). Asas Statistik Penyelidikan Edisi Ke-2. doi:10.1017/CBO9781107415324.004

Putri, W. S. R., Nurwati, R. N. \& Budiarti S, M. (2016). 7 Pengaruh media sosial terhadap perilaku remaja. Prosiding ks:riset \& pkm, 3(1), 1-154.

Ramli, M. A., Hamdan, M. N., Jamaluddin, M. A. \&\&Aminuddin, A. Q. (2015). Penyebaran Maklumat Palsu Berkaitan Produk Halal Dan Implikasinya Terhadap Industri Halal. Conference Paper, (April), 1-17. doi:10.13140/RG.2.1.3308.3361

Rohimah, S. (2017). Efektivitas Manajemen Komunikasi Dakwah Melalui Grup Whatsapp Massenger Propagation Communication Management Effectiveness Dakwah Whatsapp Group Massenger Siti Rohimah A . Pendahuluan Komunikasi merupakan proses penyampaian pesan oleh komunikator kepada k. Prosiding Komunikasi Penyiaran Islam, 3(1), 101-106.

Rusinah Joned \& Sudirman Asmadi, (2003). Metodologi Penyelidikan: Aplikasi Statistik dan Ethnograph Untuk SOSIAL SAINS. Modul Latihan.Hakcipta Terpelihara 2003.

Saari, N. A. S. \& Mahiyaddin, R. (2017). Analisis linguistik terhadap penggunaan media sosial dalam kalangan pelajar di ipts 1(1), 151-165.

Syed Chear, S. L. (2017). Pengajaran dan Pembelajaran Melalui Aplikasi Whatsapp dan Telegram di Universiti Swasta. Jurnal Pendidikan Malaysia, 42(2). doi:DOI: http: //dx.doi.org/10.17576/JPEN2017-42.02-02 Pengajaran

Tahir, Z. \& Mohd.Yusof, M. N. (2017). Kepentingan Penggunaan Media Sosial Teknologi 12(3).

Wan Embong, W. H., Yaakob, Z., Rohani, Z. H., Abidin, M. \& Ibrahim, F. (2015). KajianTinjauan : Buli Siber di Kalangan Mahasiswa Universiti Teknologi Malaysia 1-20. 